\title{
Expressividade e Frequência de uso: aspectos pragmáticos e cognitivos da gramaticalização
}

\section{Expressiveness and Frequency of Use: Pragmatic and Cognitive Aspects of the Grammaticalization}

Lorenzo Vitral

Universidade Federal de Minas Gerais (UFMG), Belo Horizonte, Minas Gerais, Brasil. lorenzovitral@gmail.com

Resumo: O artigo busca explicitar a intuição de Meillet (1912) de que os fenômenos de gramaticalização resultam da tensão entre a expressividade e a frequência de uso das formas da língua. Tratando a expressividade por meio da noção de subjetificação (TRAUGOTT; DASHER, 2005; LANGACKER, 2006), formulamos as seguintes questões: (1) o que quer dizer mais conteúdos e por que (e de que maneira) mais formas implicam mais conteúdos?; (2) o que quer dizer menos conteúdos e como se explica sua relação com a redução de formas? Por meio de princípios da pragmática neo-griceana e da análise da dupla negação em português, procuramos explicar como os falantes extraem conteúdos que se associam à sua subjetividade, o que estaria no cerne do fenômeno de inovação linguística. Após discussão sobre a noção de abstração e sua relação com a subjetividade, propomos que a perda de expressividade das formas se deve a seu espraiamento no sistema da língua e entre os falantes.

Palavras-chave: Gramaticalização; Subjetificação; Pragmática; Abstração; Dupla negação.

Abstract: This article seeks to clarify Meillet's supposition (1912) that the phenomena of grammaticalization result from tension between the expressiveness and the frequency of use of language forms. Treating 
expressiveness through the notion of subjectification (TRAUGOTT; DASHER, 2005; LANGACKER, 2006), we formulated the following questions: (1) What does more content mean? And why (and how) do most forms imply more content; (2) what does less content mean? And how does it explain its relation to the reduction of forms? Through the principles of Neo-Gricean pragmatism and the analysis of double negation in Portuguese, we seek to explain how speakers extract content that are associated with the subjectivity of speakers, which would be at the heart of the phenomenon of linguistic innovation. After discussing the notion of abstraction and its relation to subjectivity, we propose that the loss of expressiveness of forms is caused by its expansion in the language system and among speakers.

Keywords: Grammaticalization; Subjectification; Pragmatics; Abstraction; Double Negation.

Recebido em 16 de setembro de 2014. Aprovado em 04 de novembro de 2014.

\section{Introdução}

A intenção deste texto é explorar certas consequências teóricas da intuição central, exposta por Meillet no texto inaugural da perspectiva da gramaticalização, sobre a motivação da inovação linguística. Os seguintes trechos mostram-nos a proposta do autor de que precisamos (MEILLET, 1982, p. 139 e 140-141 (=1912)):

A constituição de formas gramaticais pela degradação progressiva de palavras anteriormente autônomas se torna possível por meio de procedimentos que consistem num enfraquecimento da pronunciação, da significação concreta das palavras e do valor expressivo das palavras. (tradução nossa) ${ }^{1}$

\footnotetext{
${ }^{1}$ La constitution de formes grammaticales par dégradation progressive de mots jadis autonomes est rendue possible par les procédés... qui consistent... en un affaiblissement de la prononciation, de la signification concrètes de mots et de la valeur expressive des mots.
} 
As línguas seguem assim um tipo de desenvolvimento em espiral: elas acrescentam palavras acessórias para obter uma expressão intensa; essas palavras se enfraquecem, se degradam e acabam por se tornar simples instrumentos gramaticais; acrescentam-se novas palavras ou palavras diferentes buscando a expressão; o enfraquecimento recomeça e assim sem fim. (tradução nossa) ${ }^{2}$

Para ele, como se vê, os fenômenos de gramaticalização resultam da tensão entre a expressividade e a frequência de uso das formas da língua por parte dos falantes, ou seja, na medida em que sua frequência de uso aumenta, uma dada forma perde expressividade.

Supondo que a proposta de Meillet capta a essência dos processos de inovação linguística, a questão que se coloca é por que o surgimento e a evolução dos processos de gramaticalização se submetem a uma dinâmica que pode ser comparada ao movimento de uma báscula, ou seja, numa ponta, a expressividade da forma e, na outra ponta, sua redução formal/semântica.

À primeira vista, essa relação entre a expressividade e a redução formal/semântica de um item parece ser de natureza icônica, ou seja, quanto mais formas são empregadas, mais conteúdos são veiculados; e, quanto menos formas são empregadas, menos conteúdos são veiculados. Essa visão dos fatos já foi explorada por Givón $(1975 ; 1990)$ ao prever que informações maiores, mais importantes ou menos previsíveis tendem a ser expressas com maior quantidade de material linguístico.

Essa formulação do problema talvez possa servir de ponto de partida para tentar explicitar o que está em jogo. Tendo como baliza buscar entender a motivação da inovação linguística nos processos de gramaticalização, trata-se assim de (1) caracterizar o que quer dizer mais conteúdos e explicar por que e de que maneira mais formas implicam mais conteúdos; e (2) caracterizar o que quer dizer menos conteúdos e explicar sua relação com a redução de forma e de conteúdo.

Buscaremos, neste artigo, tratar, ainda que de forma parcial, dos dois temas supramencionados. Em relação ao tema (1), retomo

\footnotetext{
${ }^{2}$ Les langues suivent ainsi une sorte de développement en spirale: elles ajoutent des mots acessoires pour obtenir une expression intense; ces mots s'affaiblissent, se dégradent et tombent au niveau de simples outils grammaticaux; on ajoute de nouveaux mots ou des mots differents en vue de l'expression; l'affaiblissement recommence et ainsi sans fin.
} 
a proposta desenvolvida em VITRAL (2012) acerca do fenômeno da inovação linguística e de sua relação com o conceito de subjetificação. Assim, mais conteúdos, no sentido supracitado, advêm da subjetividade dos falantes: inovações são engendradas a partir de motivações que se associam à subjetividade dos falantes, a qual, por sua vez, é chamada a se expressar devido, sobretudo, a um mecanismo psicossocial nomeado de luta por reconhecimento (HONNETH, 2003). Resumiremos essa proposta na seção 1 , a seguir. $\mathrm{O}$ desenvolvimento do tema (1) procura ainda relacionar, na seção 2 , o fato de extrairmos mais conteúdos a partir de mais formas com as máximas da conversação estabelecidas por Grice $(1975 ; 1989)$ e exploradas pela pragmática neo-griceana de Horn (1985; 1993; 2006; 2007), Levinson (1991a; 2007) e Huang (2009). A fim de trazer alguma base empírica para nossa discussão, examinaremos, na seção 3, por meio da hipótese proposta, o fenômeno da dupla negação em português. Na seção 4, examinaremos o tema (2) acima com base numa discussão acerca da possibilidade de se tratar a noção de menos conteúdo por meio da alegada propriedade de abstratização dos processos de gramaticalização. Recusada essa hipótese e levando em conta a noção de extensão, propomos que a impessoalização adquirida pelas formas que se gramaticalizam advém de seu espraiamento no sistema da língua e entre os falantes. Apresentaremos, em seguida, nossas considerações finais.

\section{VITRAL (2012): subjetificação e luta por reconhecimento}

Partimos da hipótese de que, se pretendemos entender a motivação da inovação linguística, é necessário explicitar o que quer dizer expressar mais ou menos conteúdos. Em VITRAL (2012), desenvolvemos a proposta de que a busca de inovação no emprego da língua advém da necessidade de o sujeito se constituir diante de um mecanismo psicossocial denominado luta por reconhecimento. Essa noção foi explorada a partir do texto de Honneth (2003) que, como veremos abaixo, a retoma a partir de sua origem em textos da filosofia moderna.

Para desenvolver essa proposta, nosso texto tomou como objeto empírico a criação e evolução, nas línguas em geral, das formas perifrásticas compostas por um auxiliar e um verbo lexical. Com base em análises que se iniciam por Meyer-Lubke (1914), passando por Vossler (1922); Meillet (1928); Bally (1935); Damourette e Pichon (1936); Mattoso Câmara (1956) e Coseriu (1957), Fleischman (1982) 
propõe um tratamento contemporâneo para a formação do futuro perifrástico, partindo da constatação de que, acoplada à alternância de formas sintéticas e analíticas na formação dos tempos verbais, ocorre, concomitantemente, alternância no que refere à expressão dos conteúdos de temporalidade e de modalidade das formas, de maneira que a quantidade de temporalidade ou de modalidade está sujeita a flutuações. Quanto mais a forma expressar o conteúdo de tempo propriamente dito menor é a sua força modal e vice-versa, ou seja, quando mais conteúdos modais forem expressos - como obrigação, volição, permissão, certeza, probabilidade... - menos nítida é a expressão do tempo. Assim, quando a expressão da temporalidade se torna nítida, os falantes partem em busca de uma nova forma (no mais das vezes, perifrástica) que reponha a modalidade perdida no processo de temporalização. Fleischman (1982, p. 18) complementa sua proposta, elaborando a noção de relevância do presente, que está subjacente à formação das formas verbais compostas. Essa noção é definida da seguinte maneira:

Relevância do presente: uma noção aspectual que assinala o estabelecimento de uma conexão entre "agora" e "não agora"; um evento cronologicamente não presente (passado ou futuro) é visto como psicologicamente associado ao tempo presente. (itálicos da autora; tradução nossa) ${ }^{3}$

Além da formação do futuro, mostramos, tomando por base a análise de Kurylowicz (1966) para o present perfect, que a noção acima é também pertinente para a formação dos tempos perifrásticos do passado. Em resumo, a formação das formas perifrásticas dos dois tempos é alimentada correntemente pelas formas do presente, isto é, os auxiliares, cooptados, num primeiro momento, por processos de gramaticalização, estão no tempo morfológico presente. Com base ainda na noção acima, propomos, enfim, que a inovação linguística, no que se refere à formação dos tempos compostos obedece à seguinte dinâmica: visto que aquilo que deve ser enunciado pelo sujeito é, evidentemente, situado em relação ao tempo do evento, as formas de expressão do tempo, na medida em que vivem sua evolução na língua, vão sendo interpretadas gradativamente

\footnotetext{
3 "Present relevance: un aspectual notion signaling the establishment of a connection between "now" and "not-now"; a chronologically nonpresent (past or future) event is viewed as psychologically linked to present time"
} 
como se reportando a eventos situados em tempos cada vez mais distantes do presente; para trazer a enunciação para o presente, o sujeito coopta itens que originalmente exprimem o presente e os faz instrumentos de expressão do passado e do futuro. As inovações provocam, portanto, a expressão de passados e futuros sentidos como mais próximos do presente.

A questão trabalhada na sequência do que vimos até aqui foi a razão de os falantes criarem as inovações analisadas a partir do tempo presente. Partimos da noção de subjetificação, que retoma, como se sabe, intuições capitalizadas por Benveniste (1976), ao tratar da expressão do sujeito da enunciação e é utilizada, hoje em dia, por várias perspectivas teóricas (cf. seção 4, na qual damos mais detalhes sobre essa noção). Levamos em conta, em VITRAL (2012), a perspectiva de Langacker (1990; 2006), que destaca os recursos da linguagem que permitem ao falante exprimir conteúdos que dizem respeito à relação entre sua localização e a dos participantes do evento no que concerne às dimensões de tempo e lugar.

No nosso ponto de vista, o fundamento da relevância do presente pode se valer da proposta de Langacker no seguinte sentido: o tempo presente deve ser visto como um recurso de linguagem que funciona como um tipo de "eixo", conectando a enunciação e o sujeito, o que determina aspectos de forma das escolhas dos falantes. O tempo presente é ainda um recurso que permite levar formas de uso normalizado a serem convertidas em formas de uso inovador.

Continuando nossa articulação de conceitos, a pergunta seguinte foi a que se deve a necessidade do falante de buscar a inovação linguística, impondo-se como sujeito na expressão de sua subjetividade. Para examinar essa questão, utilizamos a noção de luta pelo reconhecimento que, oriunda na história na filosofia moderna, tendo como principais referências as contribuições de Maquiavel $(1515)=1983)$, de Hobbes $(1651)=1983)$, Hegel (1893)=1992), é desenvolvida por Honneth (2003), que se baseou também no trabalho de Mead (1934)=2006).

Assim, na nossa visão dos fatos, ao buscar a inovação, o falante visa a se constituir como sujeito nas trocas simbólicas estabelecidas na luta pelo reconhecimento. O que o falante deseja é, em última instância, o próprio reconhecimento pelo outro de seu estatuto como sujeito. O mecanismo psicossocial da luta pelo reconhecimento tem o papel, na filosofia moderna, de estabelecer a coesão orgânica da 
sociedade na medida em que permite o reconhecimento intersubjetivo da particularidade de cada indivíduo. A partir daí, valemo-nos de Mead, para quem um sujeito só pode adquirir consciência de si mesmo à medida que desenvolve a habilidade de se perceber a partir da perspectiva, simbolicamente representada, de uma segunda pessoa. Após isso, Mead preocupa-se em explicitar como se estabelecem, advindas da relação com o outro, as noções morais que introjetamos. Ele propõe uma ideia, também desenvolvida por autores de horizontes teóricos distintos ${ }^{4}$ de que as normas sociais que adquirimos vêm a partir do outro: é a partir do que supomos que o outro aprova ou desaprova que formamos nossas normas morais internas. Mead chama isso de outro generalizado. Assim, na medida em que a criança em desenvolvimento reconhece seus parceiros de interação pela via da interiorização de suas atitudes normativas, ela própria pode saber-se reconhecida como um membro de seu contexto social de cooperação. Ocorre, assim, a inclusão e a adequação do sujeito a um grupo ou a uma comunidade. Mas há, por outro lado, uma impulsividade que leva o sujeito a divergir das normas sociais, buscando se satisfazer individualmente e reivindicando, em sua comunidade, a legitimidade de seus desejos como indivíduo; ou, em outras palavras: o sujeito procura constantemente ampliar as normas de maneira a conferir expressão social à impulsividade e à criatividade do seu eu. ${ }^{5}$ Enfim, haverá sempre, no sujeito, uma tensão entre a vontade da comunidade internalizada por meio de normas e as pretensões de individuação, o que é o motor da criatividade.

Desenvolver essas propostas em profundidade exigiria explicitar o papel da noção de identificação e de suas implicações na formação do aparelho psíquico, ${ }^{6}$ e também como se dá a implementação social das inovações, ${ }^{7}$ mas não o faremos aqui.

Propomos, porém, um meio, que deverá ser explicitado, de transplantar essas ideias para o campo da inovação linguística. A questão que nos interessa é a seguinte: como pensar a evolução social, no sentido de Mead, e sua projeção, consequências ou implantação na evolução da língua, ou, em outras palavras, como é implementada a

\footnotetext{
${ }^{4}$ Cf. LACAN, 1966a; $1966 b$.

${ }^{5} \mathrm{Cf}$. WINNICOTT, 1975.

${ }^{6}$ Cf. BENJAMIN, 1988.

${ }^{7}$ Cf. MILROY, 1980; BORTONI-RICARDO, 2011.
} 
correspondência entre mecanismos de organização individual e social e a evolução da língua. Essa questão é, evidentemente, bastante ampla e exige um trabalho de muito fôlego para ser desenvolvida de forma minimamente satisfatória. O que foi proposto é apenas uma direção para essa reflexão, supondo que é possível pensar a inovação linguística, que ocorre nos processos de gramaticalização e de lexicalização, como uma afirmação do $e u$, o que pode implicar uma transgressão normativa no sentido de Mead.

A nossa proposta é que a inovação linguística, advinda da subjetividade, é gerada no contexto de busca de reconhecimento. A intuição de Meillet, mencionada anteriormente, pode agora ser recolocada da seguinte maneira: na medida em que uma dada forma se espraia na língua e sua frequência de uso aumenta, ela reduz sua capacidade de ser um trunfo na luta por reconhecimento por parte de um sujeito. Assim, formas inovadoras são criadas pelos falantes de maneira a reaver a capacidade de ser trunfo na luta por reconhecimento que se reduz, ou é perdida, pelas formas conservadoras. Por outro lado, é preciso ter claro que a inovação linguística não é um processo consciente no qual o sujeito tem pretensão à verdade, construída simbolicamente por atos argumentativos. No nosso caso, o falante não pretende superar o interlocutor ao criar uma inovação e sim apenas ser reconhecido no seu papel social naquela interação e, possivelmente, nem toda violação da norma teria esse papel e sim só aquelas que inovam do ponto de vista expressivo.

Vejamos, enfim, como aliamos a proposta acima com a nossa descrição acerca da relevância do presente. Como vimos, trazer o enunciado para o agora da enunciação e, como consequência, para o sujeito é o mecanismo que deflagra a criação das formas inovadoras que compõem as formas perifrásticas. Podemos considerar assim que as formas conservadoras, ao descreverem eventos cada vez mais distantes do presente, perdem seu valor expressivo, o que reduz sua capacidade de ser trunfo na luta pelo reconhecimento; as formas inovadoras - que, como vimos em relação às formas perifrásticas, fundam-se a partir de conteúdos modais - trazem a descrição dos eventos para o presente e recuperam valor expressivo que as capacita a ser trunfos na luta por reconhecimento. Portanto, o valor expressivo é reinstalado na medida em que, ao trazer a descrição dos eventos para o presente, recoloca-se o sujeito enunciador no mecanismo psicossocial do reconhecimento. 
É a partir dessas ideias, enfim, que pensamos poder explicitar o ponto (1) mencionado na introdução, ou seja, caracterizar o que quer dizer mais e menos conteúdos. Mais e menos conteúdos não se referem, assim, à quantidade de eventos narrados ou descritos e sim ao maior ou menor envolvimento subjetivo do falante no sentido que assumimos anteriormente. A questão que se coloca, a seguir, é por que razão maior comprometimento subjetivo parece implicar maior quantidade de formas. Desenvolveremos esse ponto a partir da seção seguinte.

\section{A pragmática neo-griceana e a inovação linguística}

A proposição de que maior comprometimento subjetivo implica maior quantidade de formas autoriza-nos, seguramente, a levantar objeções. Por exemplo, a opção de um falante se silenciar diante de uma pergunta que lhe é dirigida pode ser altamente expressiva de sua subjetividade, indicando uma boa variedade de estados afetivos que deixamos a cargo da imaginação do leitor. Ora, neste caso, não há forma alguma.

É preciso, portanto, refinar nossa hipótese.

Em primeiro lugar, podemos nos interrogar se há elementos específicos reveladores de subjetividade e, caso afirmativo, quais seriam eles. A questão obviamente é bastante ampla e complexa e não poderemos neste espaço desenvolvê-la satisfatoriamente. É sabido que há formas que se prestam por excelência à expressão da subjetividade (VITRAL, 2012). Tudo indica, no entanto, que quaisquer recursos da língua podem ser utilizados com essa finalidade, ou seja, mesmo quando aparentemente os falantes descrevem ou narram eventos, podemos dizer que não há neutralidade nas expressões: o narrado ou o descrito é permeado de crenças, concepção de mundo ou conteúdos emocionais dos falantes.

A expressão da subjetividade não parece, pois, exigir necessariamente quantidade crescente de formas. No entanto, tendo em vista nossos objetivos, podemos precisar nossa hipótese da seguinte maneira: é a criação de formas inovadoras, as quais, na origem, como vimos, são veículos de subjetividade, que implica a execução de mais formas do que as formas conservadoras com o mesmo valor de verdade. Para desenvolvê-la, apoiamo-nos na perspectiva da pragmática lexical neo-griceana.

Essa teoria, desenvolvida, como apontamos na introdução, a partir de Grice $(1975 ; 1989)$, propõe um estudo sistemático de propriedades 
semânticas de itens lexicais que são dependentes do uso da língua, o que supõe que parte do significado de uma expressão não faz parte do que é codificado por ela. Reconhecemos nessa perspectiva o que precisamos, ou seja, os conteúdos advindos da subjetividade do falante não fazem parte, como se sabe, dos conteúdos atomizados que compõem a proposição que narra e descreve eventos.

Como é sabido, a teoria pragmática contemporânea teve seu início com a formulação, por Grice, das máximas ou princípios da conversação a partir dos quais se extraem as implicaturas conversacionais. Interessanos, especificamente, a combinação da máxima da quantidade e o item (iii) da máxima do modo que podem ser formulados da seguinte maneira, de acordo com Levinson (2007, p. 127):

(1) A Máxima da Quantidade:

(i) faça com que sua contribuição seja tão informativa quanto for exigido para os presentes fins do intercâmbio;

(ii) não faça com que sua contribuição seja mais informativa do que é exigido.

(2) A Máxima do Modo:

Seja perspícuo e, especificamente:

(iii) seja breve.

De acordo com a interpretação padrão dessa proposta, considerase que esses princípios são norteadores da conversação, de forma que, quando são, à primeira vista, violados, o ouvinte supõe que ocorre adesão do falante num nível subjacente, o que lhe permite extrair um conteúdo não manifesto. Pela máxima da quantidade, o falante é instado a dizer apenas o que exigido numa interação, e não mais do que isso, e pela máxima do modo, o falante dirá o que tiver de dizer da maneira mais econômica possível, tendo em vista exatamente o volume de formas ou recursos de linguagem empregados.

Como se sabe, as propostas de Grice foram desenvolvidas pelo que se convencionou chamar de pragmática neo-griceana. Um dos mais destacados teóricos dessa perspectiva, Horn $(1989 ; 2007)$ reexamina as máximas de Grice, defendendo a hipótese de que bastam dois princípios: o princípio $\mathrm{Q}$ (da quantidade) e o princípio $\mathrm{R}$ (da relação), que obtêm a seguinte formulação (apud HUANG, 2009, p. 122): 
(3) A. O Princípio-Q:

Torne sua contribuição suficiente;

Diga tanto quanto você possa (dado o Princípio-R).

B. O Princípio-R:

Torne sua contribuição necessária;

Não diga mais do que é necessário (dado o Princípio-Q) ${ }^{8}$ (tradução nossa)

A versão dos princípios da conversação revistos por Horn dão destaque exatamente aos aspectos previstos pelas duas máximas de Grice já comentamos. Horn extrai outras consequências desses princípios que dizem respeito, por exemplo, às implicaturas resultantes do uso de itens que exprimem escalas -, mas não nos ocuparemos desse tipo de fenômeno neste texto.

Como se vê, há compatibilidade entre as previsões da teoria pragmática e o que precisamos, ou seja, explicitar o que permite aos falantes extrair conteúdos adicionais a partir do emprego de mais formas. Assim, se o falante gera uma forma inovadora ou, ao dispor de recursos de linguagem que têm o mesmo valor de verdade, opta por utilizar a forma mais longa entre elas, o ouvinte é chamado a inferir um conteúdo adicional, subjacente, que introduz aspectos de conteúdo associados à subjetividade do falante. Na próxima seção, discutiremos o fenômeno da dupla negação com o intuito de ilustrar e comprovar nossa abordagem.

\section{A dupla negação e a inovação linguística}

Nesta seção, analisamos o fenômeno da dupla negação com o intuito de ilustrar as hipóteses apresentadas nas seções 2 e 3 . Como é sabido, esse fenômeno é de ampla produtividade nas línguas em geral e tem recebido, ao longo do tempo, tratamentos teóricos sob diversas

\footnotetext{
${ }^{8}$ A. The Q-principle:

Make your contribution sufficient;

Say as much as you can (given the R-principle).

B. The R-principle:

Make your contribution necessary;

Say no more than you must (given the Q-principle).
} 
perspectivas. Vamos ilustrá-lo com os dados do português do Brasil que seguem abaixo:

(4) Maria não viajou não/ coisíssima nenhuma/ porcaria nenhuma etc. ${ }^{9}$

Em construções como (4), a partícula pré-verbal não (ou suas equivalentes reduzidas como num, nu e $n$ ' (SOUSA, 2010) se faz acompanhar por itens negativos pós-verbais, constituídos pela forma plena não ou por expressões negativas, bastante variadas, compostas por nomes, quantificadores, advérbios e outros itens.

A análise pioneira de Jespersen (1917), por meio da sua proposta de um ciclo diacrônico da negação, mostrou-nos que é preciso levar em conta, como uma tendência geral nas línguas, o fato de a partícula negativa pré-verbal tender à redução fônica, o que, aparentemente, de maneira concomitante e em contrapartida, incita à captação de constituintes pós-verbais que adquirem, de forma processual, valor negativo, o qual se esvaiu devido à redução da negação pré-verbal. O percurso das formas francesas ne...pas é, usualmente, citado como um exemplo prototípico dessa alternância entre constituintes negativos pré-verbais e pós-verbais.

Muitas das tentativas de explicitar o ciclo de Jespersen partem da constatação de que, pelo menos num determinado estágio do processo, as construções com apenas o item negativo pré-verbal e as construções com dupla ocorrência de constituintes negativos se equivalem, podendo ser vistas como variantes. Colaboram também para esse ciclo os processos de gramaticalização, tendo em vista o fato de itens, de variadas classes gramaticais, adquirirem conteúdo negativo de forma gradual e também o fato de a redução das formas negativas pré-verbais poder ser descrita

\footnotetext{
${ }^{9}$ Como se sabe, há uma multiplicidade de expressões que podem compor o fenômeno da dupla negação. Observem-se os seguintes exemplos adicionais (de ROCHA, 1992):

(i) Ele não tem um tostão furado; eu não entendi patavina/picas desse filme; ninguém sabe porra/bosta/merda nenhuma disso; ele não falou gato; você não tem um pingo de educação; a Márcia não me dá a mínima (bola); ninguém aqui bebe uma gota; ela não fez ISSO (acentuado) pra me ajudar; não posso ficar nem mais um minuto com você (A. Barbosa); nenhum aluno disse uma palavra; você não vai sair daqui nem fudendo/pagando/a pau; você não vai sair nem que a vaca tussa.
} 
como os estágios de cliticização e de afixação previstos nos processos desse tipo (VITRAL, 1999; KIPARSKY; CONDORAVDI, 2006).

Quando nos atemos, por outro lado, a aspectos de uso da língua, ao comparar as construções com negação única pré-verbal e as construções com dupla negação, é possível destacar, de maneira bastante nítida, que são veiculados conteúdos de natureza pragmática. Os exemplos de dupla negação que listamos anteriormente já dão uma ideia do exercício da função expressiva da língua por meio das expressões compostas de dupla negação: a composição de expressão negativa com o superlativo coisíssima é bastante transparente nesse sentido. Vejamos, a seguir, o que se pode destacar acerca da natureza pragmática da dupla negação.

É preciso ter em mente, em primeiro lugar, que a função expressiva do fenômeno esteve sempre em relevo nas análises propostas em várias perspectivas. Veja-se, por exemplo, a afirmação de Kröll (1952, p. 3) de que a negação múltipla, "sobretudo, na linguagem popular, é um tipo frequentíssimo de negação, testemunhando grande abundância de afecto." Em análises contemporâneas do fenômeno, como nos mostra Schwenter (2005, p. 1429), é comum depararmos com a classificação da dupla negação como "enfática" ou "reforçadora", o que já era previsto pela descrição do ciclo de Jespersen, e também "contrária à expectativa" (FURTADO DA CUNHA, 1996) ou "pressuposicional" (SCHWEGLER, 1991; RONCARATI, 1999). Nessa última classificação, encontramos a tentativa de nomear conteúdos de natureza pragmática já apontada também por Givón (1979, p. 109) quando afirma que "negatives are consistently more marked in terms of discourse-pragmatic pressupositions..."

No intuito de tornar discretos os conteúdos pragmáticos veiculados pela negação, pode-se partir da distinção entre negação interna e externa (DAHL, 1979; RAJAGOPALAN, 1982; HORN, 1989). Quando é considerada interna, a negação tem o papel de inverter o valor de verdade de uma proposição, ou seja, uma oração $(\mathrm{O} 1)$ é convertida em outra $(\mathrm{O} 2)$ de maneira que $\mathrm{O} 2$ é verdadeira se $\mathrm{O} 1$ é falsa ou viceversa. Vejamos os exemplos de Dahl (1979 apud SOUSA, 2012, p. 35):

(5) a. It is not raining.

b. It is false that it is raining.

c. It is not the case that it is raining. 
As orações em (5) são orações negativas de acordo com a definição proposta. Porém, (5a) se distingue de $(5 \mathrm{~b}$ e c c) por não conter uma oração subordinada, o que faz com que as duas últimas sejam mais bem definidas, na realidade, como denegação. Nesse caso, que podemos chamar de externa, a negação não nega simplesmente o evento, mas também a verdade de um conteúdo implícito, suposto pelo falante, que é a avaliação do interlocutor de que está chovendo.

Schwenter (2005) e Sousa (2012) dão destaque e se ocupam, em análises detalhadas, das propriedades funcionais ou pragmáticas do fenômeno da dupla negação no português do Brasil. De acordo com o primeiro, que adota o modelo de Price (1992), o status de um NP referencial acerca da conhecida dicotomia entre elemento dado e novo é determinante no emprego bem formado da negação simples e da negação dupla. Segundo o autor, a ocorrência de um item negativo numa posição pós-verbal, precedida por uma partícula negativa pré-verbal, é bem sucedida em contextos como o seguinte:

(6) Falante A: Você desligou o fogão, né?

Falante B: Nossa! Não desliguei não!

Em casos como (6), está implícito, como informação dada, que o falante B desligou ou deveria ter desligado o fogão, e é exatamente essa crença do falante A que é negada pelo recurso da dupla negação. A negação nesse tipo de ocorrência mostra-nos, assim, a incidência da instância subjetiva, já que se trata de o falante se dirigir ao ouvinte no intuito de infirmar o que este pressupõe como fato. Assim, a dupla negação, de acordo com Schwenter, não poderá ser bem formada em casos como o que está abaixo, situado no contexto que descrevemos entre colchetes:

(7) [A falante caminha pela rua e, de repente, se lembra de que se esqueceu de desligar o fogão]

Nossa! (Eu) não desliguei o fogão (\#não)!

Como o enunciado é uma voz interna, dirigida à própria falante, o que o definiria como informação nova, o uso da dupla negação, não é bem sucedido. 
Além da informação considerada elemento dado, Schwenter admite também que a dupla negação pode ainda ocorrer em contextos nos quais um conteúdo é inferido pelo falante. Veja-se um exemplo:

(8) [O falante vê o interlocutor pegando um casaco que é muito pesado para a temperatura]

Não tá muito frio não!

Em (8), o falante denega, na realidade, a crença de seu interlocutor de que está muito frio.

Independentemente da discussão acerca de quais outros contextos admitem a dupla negação, a proposta de Schwenter tem o mérito de tentar explicitar a intuição persistente, em vários trabalhos, de que o emprego da negação e, mais especificamente, como vimos, da dupla negação, está estreitamente relacionada com conteúdos pragmáticos ou não exclusivamente gerados composicionalmente pelos itens da proposição que se enuncia.

Sousa questiona os dados de Schwenter afirmando que, embora a dupla negação ocorra com mais frequência quando paira uma informação dada, também seria possível o emprego dessa estrutura em contextos nos quais teríamos informação nova, como na seguinte ocorrência:

(9) A. Tentei te ligar ontem, mas você não atendeu.

B. Meu celular não tá funcionando não.

Considerando que tanto a avaliação dos dados de Schwenter quanto a de Sousa estão corretas, e reaproveitando a ideia do ciclo de Jespersen, adotamos a proposta de que a instalação da dupla negação, com a multiplicidade de expressões negativas inovadoras e a redução de partículas negativas pré-verbais, é processual e retratável por meio de um ciclo no qual as construções com dupla negação tendem à neutralização no que concerne aos conteúdos pragmáticos. Na nossa visão, tudo se passa de acordo com as seguintes etapas:

- Etapa (1): no momento da instalação de uma expressão negativa inovadora, juntamente com outra partícula negativa pré-verbal, a interpretação da estrutura inclui conteúdos pragmáticos, como 
foi o caso nas ocorrências descritas por Schwenter por meio das noções de elemento dado e proposições inferidas. Há, nesse caso, especialização das estruturas negativas na medida em que a negação simples é reservada para os contextos de elemento novo e ausência de conteúdos inferidos.

- Etapa (2): no momento seguinte, na medida em que são usadas também para contextos de informação nova, as construções com dupla negação passam a variar com aquelas que contêm negação simples. Como se percebeu, o ambiente está criado para que possa haver um processo de variação e mudança que, afinal, somos obrigados a reconhecer, como o atesta o exemplo prototípico da partícula francesa pas a qual substitui, na fala, a estrutura com dupla negação e inúmeras análises de processos de mudança constatados por análises em tempo real e em tempo aparente (VITRAL, 1999).

Na nossa descrição dos fatos, é importante ter em mente também que o fato de Sousa (2012, p. 73) ter apontado que a estrutura da dupla negativa ocorre com mais frequência em contextos de informação dada é um índice relevante para considerar que a neutralização da estrutura com dupla negação é posterior ao estágio em que essa estrutura era condicionada por aspectos pragmáticos.

É fundamental destacar, enfim, que é apenas na etapa inicial do processo que uma expressão que participa de uma estrutura com dupla negação tem o poder de incitar conteúdos pragmáticos, ou, em outras palavras, é apenas no momento em que são reconhecidas como formas inovadoras que as expressões de dupla negação dispõem de valor pragmático.

Nossa descrição dos fatos ajuda a entender a razão da profusão de expressões de dupla negação na nossa língua e nas línguas em geral (KRÖLL, 1952 sobre listas de expressões negativas de vários estágios do português). Ora, na medida em que expressões com dupla negação perdem seu estatuto inovador, se neutralizam e adentram o padrão linguístico, os falantes criam novas expressões com dupla negativa com o intuito de garantir o poder expressivo que se esvai. Nos termos do que propomos na seção 1 , é o estatuto de trunfo no mecanismo nomeado de luta por reconhecimento que é perdido nesse processo. A recorrente cooptação de itens de variadas categorias para compor a expressão da 
negação, como é característico de processos de gramaticalização desse tipo, advém, portanto, dessa perda do estatuto de trunfo, forçando os sujeitos a buscar a inovação.

Estamos agora em medida de retomar os princípios pragmáticos da Quantidade e da Relação propostos por Horn, já expostos, e relacionálos com a descrição da negação, realizada com vistas a abordar a questão que colocamos na introdução, a saber, explicar por que e de que maneira mais formas implicam mais conteúdo.

Já vimos que mais conteúdos se referem à maior expressão subjetiva do falante. A viabilização da expressão subjetiva decorre dos princípios pragmáticos supracitados, ou seja, espera-se, numa interação discursiva, que o falante seja o mais eficiente possível e se sirva do menor número de recursos possível. Assim, se o falante, em lugar da negação simples, emprega o recurso da dupla negação no estágio em que esse recurso é inovador, ele insere, além do que se extrai da composição dos itens léxicos envolvidos, um conteúdo adicional de natureza subjetiva.

A nossa expectativa é que a inteligibilidade alcançada com essa proposta possa ser estendida a outros fenômenos de linguagem, tais como a formação das perífrases verbais, como foi explorado em Vitral (2012), as perífrases conjuncionais ou preposicionais e o redobro pronominal. São sugestões de fenômenos que talvez possam ser analisados nessa mesma perspectiva.

\section{A operação de abstração e a redução de formas}

\subsection{Conteúdos subjetivos versus conteúdos abstratos}

Vimos anteriormente que mais conteúdo é, na verdade, a expressão da subjetividade do falante. Por outro lado, subsiste a necessidade de algum encaminhamento do contraponto desse fenômeno, isto é, o tema (2) apontado na introdução: como entender a noção de menos conteúdos e sua relação com a redução de formas. Dito de outra maneira e retomando as características dos processos de gramaticalização: por que menos conteúdo é menos expressivo? Uma maneira de desenvolver esse ponto é examinar o que quer dizer menos subjetivo.

É preciso distinguir de início as duas dimensões envolvidas nos processos de gramaticalização, ou seja, alega-se que ocorrem 
a redução de forma e a redução de conteúdo. Parece haver, porém, uma correspondência entre essas duas dimensões, quer dizer, menos forma, ainda que assimetricamente (VITRAL; RAMOS, 2006b), faz-se acompanhar de menos conteúdo.

À primeira vista, pode-se pensar que menos conteúdo, já que menos subjetivo, deve exprimir fatos descritos ou narrados de forma objetiva, o que pode incluir, como é usual na descrição dos processos de gramaticalização, levar em conta a abstratização gradual do significado, isto é, quanto mais gramaticalizado, mais abstrato é o conteúdo veiculado.

Nessa articulação de conceitos, parece se instalar uma oposição entre conteúdos subjetivos e conteúdos abstratos. Vamos explorar, então, o que parece ser uma dicotomia e nos perguntar se há sentido em dizer que um conteúdo subjetivo se opõe a um conteúdo abstrato.

Para desenvolver essa questão, é preciso, inicialmente, definir o que podemos entender como abstração. A conceituação dessa noção, como se sabe, é tão difícil quanto antiga, tendo em vista a origem grega do termo e seu desenvolvimento subsequente na história do conhecimento. Faremos uma breve discussão sobre esse tema a seguir.

\subsection{Abstração: um pouco de história}

Como é sabido, a oposição concreto/abstrato está presente em toda a história do pensamento filosófico e, como não poderia deixar de ser, tem larga influência no pensamento sobre a linguagem. Na realidade, existem, pelo menos, cinco acepções de abstração, que se complementam, e a partir das quais imaginamos poder derivar o mesmo tanto de acepções de concreto. Destacaremos as seguintes acepções de abstrato:

1. Abstração como extração: baseada na etimologia de abstrahere "retirar ou extrair" (utilizada pelos medievais Abelardo, Tomás de Aquino, William de Occam, entre outros), um nome abstrato decorre de uma operação mental que extrai uma propriedade ou qualidade de um outro termo e a considera-nesse ponto se instala o debate ontológico acerca da natureza dessa propriedade - como detentora, de alguma maneira, de existência independente; é caso, por exemplo, de tristeza, abstraída de triste (MATTOSO CÂMARA, 1985, p. 38; WILMET, 1996, p. 67; GREVISSE, 1980, §387)).

2. Abstração como o imaterial: essa acepção é, provavelmente, a mais persistente nos manuais gramaticais e se associa mais diretamente ao 
nosso senso comum acerca dessa noção. O papel dos cinco sentidos, isto é, a visão, a audição..., é-lhe fundamental na medida em que é por exclusão que distinguimos os termos considerados abstratos. Assim, é concreto o ser ou o objeto que é ou pode ser captado por um dos sentidos e serão abstratas as entidades que não se deixam captar por eles.

3. Abstração como generalização: é quando nos referimos a uma entidade não específica como em Um governante deve ser sensível às necessidades da população. Como se vê, o sintagma nominal um governante não denota uma pessoa específica, contingente, e sim os governantes em geral.

4. Abstração como categorização: vale a pena distinguirmos a acepção (3) da que estamos apontando em (4), ou seja, neste caso, trata-se da aplicação de uma operação de categorização, ou classificação de uma entidade, como em aquele bicho é uma ema. O papel da categorização na história do pensamento filosófico é, evidentemente, fundamental, já que, dentre as razões principais, coloca a questão da natureza do que na idade média se chamou de o problema dos universais (LIBERA, 1996, p. 35; SOWA, 2005, p. 145). Como se sabe, no século III, o debate foi introduzido, por Porfírio, no Isagoge, um texto sem pretensões teóricas que serve de prefácio à abordagem aristotélica das categorias. A partir desse texto, os medievais elaboraram uma hierarquização de predicados que ficou conhecida como a árvore de Porfirio. Em resumo, a árvore pode ser transcrita da seguinte maneira:

- Substância - (corporal ou incorporal)

- Corpo - (animado ou inanimado)

- Ser vivo - (sensível ou insensível)

- Animal - (racional ou irracional)

- Racional - (o homem) 
Esses predicados são descritos como conceitos que permitem categorizar entidades, e esses conceitos - na concepção nominalista - são de natureza abstrata, ou seja, não são da mesma ordem de realidade que as entidades concretas que são categorizadas. Assim, ainda na perspectiva nominalista, categorizar uma entidade como uma ema, por exemplo, é reconhecer uma entidade específica como um representante da categoria ema, e essa categoria, sendo um incorporal, é, portanto, abstrata. A taxonomia lineana é exemplo por excelência de desenvolvimento da árvore de Porfirio.

5. Abstração como derivação: o que é abstrato, nessa acepção, é a palavra derivada por meio de um sufixo: a partir, por exemplo, dos adjetivos rápido e municipal derivamos os nomes abstratos rapidez $\mathrm{e}$ municipalidade; de verbos como descobrir e admirar geramos os nomes abstratos descoberta e admiração.

A interrelação entre as cinco acepções é bastante transparente. Observe-se, por meio do exemplo da categorização de um ser como ema, como se articulam as concepções (1), (2), (3) e (4): incluir um ser nessa categoria é uma operação mental na qual extraímos e reconhecemos certo número de propriedades da entidade categorizada que compõem um conceito abstrato, o qual é imaterial e pode ser usado também como uma generalização. A acepção (5) também se articula com as demais acepções na medida em que se trata do recurso formal - a derivação sufixal - que retrata a operação abstrativa descrita na acepção (1). Podemos chamar a acepção (5) de morfológica; enquanto a acepção (2) parece bem nomeada como ontológica; no caso de (1), chamá-la-emos de cognitiva, já que destaca a operação mental de abstrair; e (3) e (4) serão nomeadas psicológicas, pois descrevem representações mentais, conceitos, resultantes da operação abstratizante (FLAUX et al., 1996).

Também são antigas as dificuldades de classificação inequívocas de itens como concretos ou abstratos: nenhum dos critérios acima é suficiente para tanto. No mais das vezes, utilizamos essas noções de maneira intuitiva numa (ou mais) das acepções expostas acima. A fim de fazer recordar essas dificuldades, basta pensar em casos de seres imaginários como o unicórnio ou personagens como o saci-pererê, que não existem fisicamente, mas que relutamos em alocá-los como nomes abstratos; ou ainda entidades imateriais como as figuras geométricas, 
que podem ser representadas e as que não podem ser representadas como alma ou amargura; também o fato de ser derivado não garante que o nome seja abstrato e vice-versa, como é o caso de construção, que gostaríamos que designasse um referente concreto, e charme, que incluiríamos nos casos de nomes abstratos; devemos levar em conta ainda as palavras que podem designar tanto referentes concretos quanto abstratos, como por exemplo, itens como fato e coisa. Há ainda casos como Queria um pé de jabuticaba que desse frutos todos os meses em que pé de jabuticaba é concreto, mas, no exemplo, se torna imaterial.

A lista de objeções é ampla e tudo leva a crer que, em lugar de definir uma palavra como inerentemente concreta ou abstrata, vale mais a pena considerar que há gradação entre os dois extremos da dicotomia e que também devemos avaliar a possibilidade de levar em conta o emprego de palavras de maneira concreta ou abstrata. Exemplos de gradação entre os dois extremos podem ser facilmente observados em exemplos como: levanto peso na academia; calculei o peso; e estou com peso na consciência; ou, num procedimento de abstração hiperonímico, baseado em Porfírio, em meu cachorro $>$ canino $>$ mamífero $>$ animal $>$ ser. Este é o sentido da proposta pioneira de Sapir (1921) sobre graus de abstraticidade que inspira desenvolvimentos como o de Martin (1996).

Com vistas a implementar sua proposta, Martin propõe uma gradação de abstraticidade que leva em conta quatro propriedades que dizem respeito aos seguintes aspectos: 1) material; 2) representável; 3) contável; e 4) categoremático. A título de ilustração, observe-se a seguinte classificação de palavras de acordo com as propriedades acima:

\begin{tabular}{|c|c|c|c|c|}
\hline Material & Representável & Contável & Categoremático & Exemplos \\
\hline+ & + & + & + & mesa \\
\hline- & + & + & + & círculo \\
\hline+ & - & - & + & luz \\
\hline+ & - & - & - & profundidade \\
\hline- & - & - & - & liberdade \\
\hline
\end{tabular}

Como se vê, as possibilidades combinatórias são numerosas, mas os exemplos desse quadro são suficientes para ilustrar a proposta de Martin. Bem entendido, a especificação positiva para as propriedades propostas classifica a palavra como concreta e vice-versa, ou seja, 
quanto mais especificações negativas houver mais abstrata é a palavra. Precisaríamos desenvolver o "peso" de cada propriedade em relação a essa escala, isto é, se, por exemplo, a especificação negativa para o traço contável torna a palavra mais abstrata do que uma especificação negativa para o traço representável. São pontos que o autor não desenvolve e também não o faremos aqui.

Independentemente da incompletude, de alguma objeção que se possa fazer em relação às propriedades escolhidas ou ainda à classificação de palavras específicas em relação a essas propriedades, a proposta de Martin tem um mérito que nos interessa em relação aos nossos objetivos. Ora, abre-se a possibilidade de tratar mais explicitamente a intuição tradicional da abstração como uma operação mental ou cognitiva. Diremos, assim, que a abstração é uma operação cognitiva por meio da qual podemos categorizar objetos representados mentalmente. Pode-se então propor que, do fato de haver gradação, dispomos de uma operação cognitiva que tem o poder de abstratizar (ou concretizar) conteúdos, isto é, de concebê-los como concretos ou abstratos. Essa operação é inerente ao nosso sistema cognitivo e funciona, de maneira involuntária, como se representa a seguir:

$$
\text { (10) } X>X^{\prime}>X^{\prime \prime}>\ldots
$$

A fórmula acima significa que um item $X$ evolui numa cadeia de abstratização na qual $X$ ' é mais abstrato que $X, X$ " é mais abstrato que $\mathrm{X}^{\prime}$ e assim por diante.

A operação de abstração que estamos propondo não é, evidentemente, uma novidade. Ela perpassa a teoria do conhecimento e já encontrava, em São Tomás de Aquilo, uma teoria estabelecida. Para ele, o entendimento humano separa (abstrai) a "imagem intelectual" da “imagem sensível” e, dessa maneira, capta algo que está além daquilo que recebeu através da sensibilidade. São Tomás nomeia essa operação de superação (excessus): é por meio dela que a mente, ou o espírito humano, se abre para o conjunto de seus objetos possíveis. Essa visão da abstração, tratada como categorização, está subjacente em textos contemporâneos como o de Rosch (1978) quando ela propõe princípios que visam a justificar o automatismo de uma operação cognitiva que categoriza objetos. Para ela, trata-se de um recurso para disponibilizar o máximo de informação com o menor esforço cognitivo possível, o que 
é também dependente da nossa necessidade de representar mentalmente informações acerca do mundo de uma maneira estruturada e orgânica, e não aleatória ou imprevisível. A operação que categoriza objetos é também fundamental na ciência cognitiva atual como, por exemplo, no que concerne à sua aplicação em sistemas computacionais (COHEN; LEFEBVRE, 2005; SOWA, 2005).

Diremos, além disso, que a operação de abstração pode resultar na categorização de um objeto, mas, como mostraremos na seção seguinte, nem sempre isso ocorre. A operação de abstração é, portanto, fundamental no entendimento humano: é a aplicação dessa operação, na medida em que ela implica a categorização de um objeto, que permite o reconhecimento e a incorporação de uma representação mental, de maneira que esta se torna uma entidade que adentra e se articula com o nosso sistema de representações mentais e se torna disponível por meio de ativação mnemônica.

\subsection{A operação de abstração e os processos de gramaticalização}

Podemos agora voltar à nossa questão, exposta em 4.1, a respeito da aparente oposição entre conteúdos subjetivos e conteúdos abstratos. Após concebermos a abstração não como algo inerente ao conceito de cada item e sim como resultante de um tipo de operação cognitiva, vamos agora investigar se a resultante dessa operação torna-o um conteúdo menos subjetivo.

Precisamos explicitar, de início, a natureza dos conteúdos ditos abstratos gerados pelos processos de gramaticalização. Pensando, assim, nos tipos de processos de gramaticalização descritos pela teoria, é relevante saber: (1) que conteúdos são classificados como abstratos; (2) qual (ou quais) noção(ões) de abstrato, das enumeradas na seção 4.2, corresponde $(\mathrm{m})$ aos conteúdos classificados como abstratos nas análises de processos de gramaticalização. Isso feito, poderemos nos perguntar se se sustenta a oposição entre conteúdos subjetivos e conteúdos abstratos.

Também as duas tarefas que acabamos de prever são bastante amplas e exigem um trabalho historiográfico das análises gramaticais realizadas de acordo com nossa perspectiva. Faremos aqui apenas um encaminhamento desses temas que merecem análise aprofundada.

De início, já se antevê que deveremos distinguir os processos de gramaticalização dos processos de lexicalização. A distinção, com base 
em Vitral e Ramos (2006), pode ser estabelecida da seguinte maneira: tendo em vista tratar-se de dois processos de inovação linguística, o que implica que se dão no tempo e por etapas, ter-se-á lexicalização quando o item, fonte do processo, pertence a uma das categorias lexicais - como nome, verbo, adjetivo, advérbio e preposição - e passa a ser empregado como um membro de uma outra das classes lexicais. Terse-á gramaticalização quando o item fonte pertencente a uma das classes lexicais ou a uma das classes gramaticais (ou funcionais) - como auxiliar, determinante, flexão, complementizador e negação - vem a ser usado como um item de uma das classes gramaticais (ou funcionais).

Os casos de lexicalização, assim como os de gramaticalização, não parecem homogêneos, no sentido de qual (ou quais) das acepções de abstração é (são) implementada(s). Contudo, podemos ilustrar a discussão com o exemplo de um adjetivo que passa a funcionar como advérbio, como na conhecida publicidade da cerveja que desce redondo. Como se sabe, na base desse processo, há uma metáfora que, para exprimir a palatabilidade do modo de consumir a bebida, utiliza a imagem da forma de um círculo. Empregou-se, assim, uma figura representável visualmente para exprimir a avaliação favorável da suposta propriedade da bebida a qual não é representável visualmente - embora seja, evidentemente, percebida, por outro sentido. Nesse caso, podemos considerar que o uso adverbial de redondo é mais abstrato que seu emprego como adjetivo. Retomando as noções de abstração supracitadas, parece ter sido feito uso apenas da acepção de abstração como imaterialidade, ou seja, redondo, como advérbio, é imaterial quando comparado com seu uso adjetival.

Os casos de gramaticalização são diferentes do exemplo de lexicalização que acabamos de comentar. Consideremos dois exemplos: o do verbo ter que se converte num auxiliar e o do locativo latino lócus que passa a ser o operador lógico conclusivo logo da nossa língua, o qual pode ser categorizado como um complementizador. Nesses exemplos, não há extração de uma propriedade do item fonte que é atribuída ao uso alvo. Pode-se dizer, porém, que a natureza do conteúdo do uso gramatical dos itens é imaterial, já que corresponde a propriedades do sistema interno da linguagem. Se há categorização, por outro lado, não se trata de derivação hiperonímica e sim da mera inclusão de um item como membro de uma das categorias gramaticais.

Voltando, enfim, à nossa questão, trata-se de saber se os conteúdos abstratos veiculados nos dois tipos de processos são, na medida em que 
são exteriorizados, menos associados à subjetividade do sujeito falante. É evidente que o uso do aspecto, expresso por um auxiliar, ou de um enunciado articulado por um operador lógico, como nos exemplos apresentados, pode ser revelador da subjetividade do falante. A questão, na verdade, é, se na condição de forma inovadora, gerada por abstração, torna-se uma forma distante da subjetividade do falante.

Vamos responder, enfim, pela negativa, ou seja, o uso inovador de uma forma que se abstratiza pode ser, e muitas vezes é, índice de subjetividade do falante, ou seja, não é o significado mais abstrato gerado pela operação de abstração que torna o item menos subjetivo. Para deixar claro esse último ponto, tomemos, como exemplo, a leitura epistêmica de verbos modais que é considerada mais abstrata do que a leitura agentiva desses mesmos verbos (VIANNA, 2000; TRAUGOTT; DASHER, 2005). Observem-se os enunciados:

(11) Eu já posso levantar 80 quilos na academia. (leitura agentiva/capacidade)

(12) Há poucas nuvens, mas eu acho que pode chover no fim da tarde. (leitura epistêmica/probabilidade)

No enunciado (12), o modal, convertido em auxiliar, indica uma avaliação subjetiva do falante e, nesse sentido, é normalmente classificado como mais abstrato por vários autores já que faz surgir o ponto de vista do falante sobre o evento (ver, por exemplo, TRAUGOTT; DASHER, 2005 , p. 21). Pensando assim na gênese da inovação do modal com leitura epistêmica, é de se supor que esse uso foi inovador num determinado estágio da língua (VIANNA, 2000; LIGHTFOOT, 1979).

Não se pode dizer, pois, que a alegada redução semântica no caso de usos abstratos constitui um recuo da expressão de subjetividade dos falantes. Pelo contrário, a criação de usos inovadores, apoiados na subjetividade, se beneficia da abstratização dos conteúdos que, aliás, como vimos em (10), é inerente à nossa capacidade cognitiva.

Nossa conclusão, enfim, é compatível com o que pensa Langacker (2006, p. 18): uma expressão, ou o seu significado, não é inerentemente objetiva ou subjetiva de maneira que uma mudança semântica não implica que o significado se torne mais ou menos subjetivo. Ao invés 
disso, o significado de uma expressão sempre inclui aspectos subjetivos e objetivos, e a predominância de um desses aspectos depende de como o falante concebe o que tem a dizer. Assim, a subjetividade do falante pode se exprimir por quaisquer recursos da língua; mesmo quando aparentemente os falantes descrevem ou narram eventos, podemos dizer que não há neutralidade nas expressões: o narrado ou o descrito é permeado de crenças, concepção de mundo ou conteúdos emocionais dos falantes, o que, como defendemos, é a base da inovação linguística.

\subsection{O espraiamento das formas}

Eliminada a correlação direta entre abstração e menos subjetividade, podemos agora examinar outra hipótese:

(13) O distanciamento subjetivo da forma se deve a seu espraiamento, ou seja, na medida em que há aumento de extensão da forma, seu caráter subjetivo se esvai.

Vamos considerar, assim, que a incorporação ao sistema da língua e seu espraiamento em outros contextos, deixando a forma disponível para cada vez mais falantes, têm como resultado a perda da subjetividade.

Para detalhar essa hipótese, vamos considerar inicialmente o conceito de extensão e o uso que fazemos dele na hipótese formulada.

O termo extensão dispõe de, pelo menos, três acepções que se associam aos temas que estamos discutindo:

(1) De par com o conceito de intensão, que é a propriedade atribuída a uma "coisa", extensão refere-se ao conjunto de "coisas" às quais se pode aplicar determinada propriedade (CARNAP, 1955). Essa acepção de extensão é muitas vezes utilizada como equivalente ao quarto conceito de abstração que estudamos na seção 4.2, de acordo com Heine et al. (1991). No entanto, o fato de se elaborar uma categoria, que servirá para identificar um conjunto com a possibilidade de ser maior que um conjunto unitário, é, na realidade, uma consequência da operação de abstração que categoriza entidades.

(2) No caso de processos de gramaticalização, extensão pode também ser pensada como o fenômeno de espraiamento de uma forma no sistema da língua, ou seja, a extensão de contextos de emprego de uma forma. 
A fim de ilustrar como se dá o espraiamento mencionado em (2), consideremos alguns pontos da análise de Vitral (2006) sobre o percurso diacrônico da forma pronominal se, que foi analisado como um processo de gramaticalização.

Sabemos que o pronome se, de origem indo-europeia e com propriedades nominais, adentra o latim como pronome reflexivo e continua sua evolução no português compondo, inicialmente, a passiva pronominal e, em seguida, a construção de indeterminação do sujeito. $\mathrm{O}$ uso inovador de se para indeterminar o sujeito tem início com verbos intransitivos e, em seguida, ocorre sua expansão de acordo com os seguintes contextos (com base em NUNES, 1990, p. 95):

(1) a) verbos intransitivos com se de realce (Ex. Ele riu-se);

b) verbos transitivos diretos usados intransitivamente (Ex:

Come-se muito no inverno);

c) verbos intransitivos (Ex: Trabalha-se bastante neste lugar);

d) verbos transitivos preposicionados (Ex: Precisa-se de empregados);

e) verbos de ligação (Ex: É-se feliz quando se é jovem);

f) verbos ergativos (Ex: Chegou-se tarde à reunião);

g) verbos em construções passivas perifrásticas (Ex: Aqui se é visto por todos); e

h) verbos transitivos (Ex: aluga-se casas).

Embora possamos conjecturar que o pronome se, ao ser usado, inicialmente, como diz a descrição tradicional, "em qualquer pessoa junto de verbos intransitivos, servindo para realçar a espontaneidade ou energia do estado ou ação expressa pelo verbo... ir-se, rir-se, morrer-se..." (MAURER, 1951, p. 49), exiba valor subjetivo, a expansão da forma em um bom número de contextos, juntamente com sua evolução semântica - altera-se o estatuto argumental de se (VITRAL, 2006) -, tem o poder de neutralizar o impacto subjetivo da forma, deixando-a disponível, de maneira mais ampla, no sistema da língua. Ou seja, deixa-se de ser disponível, com valor subjetivo, apenas com verbos intransitivos para adentrar o sistema, ocorrendo em construções de vários tipos.

(3) Podemos, por fim, entender extensão no sentido de ampliação do número de falantes de uma comunidade de fala que empregam determinada forma. Aferir essa ampliação depende, como se sabe, de 
uma análise quantitativa que leve em conta critérios de frequência de uso e distribuição da forma de acordo com variáveis sociais.

Retornando agora à nossa hipótese, formulada em (13) acima, trata-se de saber qual (ou quais) exatamente é (ou são) a(s) acepção(ões) de extensão que estamos considerando.

$\mathrm{Na}$ realidade, as três acepções estão presentes e interrelacionadas na nossa hipótese. Tudo se passa da seguinte maneira: é a extensão do significado no sentido da acepção (1) - ainda que não esgote, como vimos, os sentidos de abstração que nos são relevantes - que capacita determinada forma a poder ser inserida em outros contextos da língua no sentido da acepção (2), o que, por sua vez, disponibiliza-a para ser empregada, como foi apontado na acepção (3), por maior número de falantes.

Não se trata, assim, de dizer, como conjecturamos na seção 4.1, que a abstração de um significado o torna inerentemente menos subjetivo, mas sim que, ao haver abstração, a extensão aumenta nos domínios que apontamos levando à uma neutralização do conteúdo da forma que a torna menos subjetiva. Pode-se, desse modo, falar de uma impessoalização da forma, na medida em que, de início, inovadora, ela se espraia na língua e torna-se disponível para os falantes de uma comunidade. Na evolução desse processo, a forma toma parte no padrão da língua, podendo, enfim, ser normalizada. Observe-se o exemplo do se apresentado anteriormente: o espraiamento do se - que em determinado estágio anterior compunha apenas passiva sintética (NARO, 1976) - tornou-se padrão, embora com transitivos diretos sem concordância com o sintagma nominal posposto, não tenha ainda encontrado legitimidade normativa.

No desenvolvimento das propostas desta seção deverá valer a pena explicitar a perda de propriedades, ou de traços, que caracteriza a extensão, no sentido (2), de cada processo de gramaticalização. Podemos pensar que, para haver aumento da extensão de um significado, traços se perdem, embora outros sejam acrescidos, o que nos leva a dizer que, na verdade, há alteração da natureza do significado da forma e não propriamente redução semântica. É interessante desenvolver assim um tratamento da perda de traços mencionada que, aparentemente, viabiliza a extensão de contextos em que determinada forma passa a poder ocorrer. São temas advindos do que avançamos, cujo desenvolvimento deixamos para outra oportunidade. 


\subsection{A redução de forma e sua motivação}

$\mathrm{Na}$ seção anterior, cuidamos de tentar compreender o chamado fenômeno de redução semântica que, aliás, recusamos na forma em que é compreendido comumente na literatura.

Resta-nos considerar o fato de, nos processos de gramaticalização, as expressões tenderem a se reduzir foneticamente. Tal propriedade desses processos é bastante saliente, já que atinge a forma, e sobre ela há muito o que fazer, sobretudo caracterizar quais são as propriedades de "queda" sonora que podem ser atribuídas à gramaticalização de um item ou de uma expressão.

Em relação ao que apontamos na introdução, interessa-nos a motivação da redução sonora com o avançar dos processos de gramaticalização. Sobre esse ponto, mencionamos apenas a proposta gerativista de um princípio de terceiro fator ("third factor principle") de computação mínima, ou seja, não exclusivo da faculdade de linguagem, mas de aplicação cognitiva mais ampla, que prevê o seguinte: pronuncie o mínimo possível ("pronounce as little as possible") (CHOMSKY, 2013 , p. 41). Esse princípio nos parece útil por uma razão adicional que é a sua compatibilidade com os princípios pragmáticos $Q$ e $R$ elaborados por Horn e utilizados na seção 3. O fato de ser relevante em relação ao ponto de vista pragmático reforça a natureza desse princípio como de terceiro fator no sentido de Hauser et al. (2002) e Chomsky (2005 e 2013).

Na aplicação que imaginamos dessa proposta, a redução gradual de formas observada nos processos de gramaticalização é engatilhada pelo princípio de economia supracitado que se torna pertinente, devido à padronização e ao espraiamento da forma advindos de sua impessoalização crescente.

Trata-se apenas de mais uma sugestão de análise que também não exploraremos aqui.

\section{Considerações finais}

A tentativa, neste artigo, foi apenas de articular algumas ideias que, caso sejam desenvolvidas, poderão trazer luz sobre as principais propriedades dos processos de gramaticalização, bem como sobre o obscuro tema das motivações da inovação linguística. 
O resultado mais consistente foi a elaboração a respeito do uso da noção de subjetificação, com as consequências que dela extraímos, e dos princípios da pragmática neo-griceana na tentativa de explicitar as intuições centrais de Meillet sobre a natureza dos processos de gramaticalização.

A reflexão sobre a noção de abstração e seu papel nos processos de gramaticalização é ainda muito incipiente, o que se deve à complexidade do tema, tendo em vista sua longevidade e suas ramificações no campo da teoria do conhecimento. Avaliamos que, pelo menos, tivemos o mérito de mostrar que não podemos lidar com essa noção da maneira intuitiva que comumente se vê nos trabalhos sobre gramaticalização.

Por fim, o papel do espraiamento das formas no sistema da língua e entre os falantes, assim como a correlação entre um princípio de economia e a redução das formas, são diretrizes de reflexão estimulantes sobre a natureza dos processos de gramaticalização que poderão ajudar no desenvolvimento de sua fundamentação teórica.

\section{Referências}

BALLY, C. Le langage et la vie. Zurich: Max Niehaus, 1935.

BENJAMIN, J. The Bonds of Love. New York: Pantheon Books, 1988.

BENVENISTE, E. Problemas de linguística geral. São Paulo: Companhia Editora Nacional, 1976.

BORTONI-RICARDO, S. M. Do campo para a cidade. Estudo sociolinguístico de migração e redes sociais. São Paulo: Parábola, 2011.

CARNAP, R. Significado e sinonímia nas linguagens naturais. São Paulo: Abril Cultural, 1985 (=1955).

CHOMSKY, N. Problems of Projection. Lingua, v. 130, p. 33-49, 2013. CHOMSKY, N. Three Factors in Language Design, Linguistic Inquiry, v. 36, n. 1, p.1-22, 2005.

COHEN, H.; LEFEBVRE, C. (Ed.). Handbook of Categorization in Cognitive Science. Amsterdam: Elsevier, 2005.

COSERIU, E. Sobre el futuro romance. Revista Brasileira de Filologia, n. 3, p. 1-9, 1957.

DAHL, Ö. Typology of Sentence Negation. Linguistics, v. 17, p. 79-106, 1979. 
DAMOURETTE, J.; PICHON, E. Des mots à la pensee: Verbe. Paris: Biblioteque du Français Moderne, 1936.

FLAUX, N.; GLATIGNY, M.; SAMAIN, D. (Éd.). Les noms abstraits. Histoire et theories. Paris: Presses Universitaires du Septentrion, 1996.

FLEISCHMAN, S. The Future in Thought and Language. Diachronic Evidence from Romance. Cambridge: Cambridge University Press, 1982. FURTADO DA CUNHA, M. A. Gramaticalização dos mecanismos de negação em Natal. In: MARTELOTTA, M.; VOTRE, S.; CEZÁRIO. M. (Org.). Gramaticalização no Português do Brasil: uma abordagem funcional. Rio de Janeiro: Tempo Brasileiro, 1996. p. 167-189.

GIVÓN, T. Cause and control: on the semantics of interpersonal manipulation. In: KIMBALL, J. P. (Ed.). Syntax and Semantics. v. 4, New York: Academic Press, 1975. p. 59-90.

GIVÓN, T. On Understanding Grammar. New York: Academic Press, 1979. GIVÓN, T. Syntax. A Functional-Typological Introduction. V. II. Amsterdam; Philadephia: John Benjamins, 1990.

GREVISSE, M. Le bon usage. Grammaire Française avec des remarques sur la Langue Française d'aujourd'hui. Gembloux: Duculot, 1980 (=1936).

GRICE, P. Studies in the Way of Words. Cambridge, MA: Harvard University Press, 1989.

GRICE, P. Logic and Conversation. In: COLE, P.; MORGAN, J. (Ed.). Syntax and Semantic, v. 3: Speech Acts, London: Academic Press, 1975. p. 41-58.

HAUSER, M.; CHOMSKY, N.; FITCH, T. The Faculty of Language: What is it, Who has it, and How did it Evolve? Science, v. 298, p. 15691579,2002

HEGEL, G. W. F. Système de la vie éthique. Paris: Payot, 1992 (=1893).

HEINE, B.; HÜNNEMEYER, B.; CLAUDI, U. Grammaticalization: a conceptual framework. Chicago: The University of Chicago Press, 1991. HOBBES, T. Leviatã. São Paulo: Abril Cultural, 1983 (=1651). (Coleção Os Pensadores)

HONNETH, A. Luta por reconhecimento. A gramática moral dos conflitos sociais. São Paulo: Editora 34, 2003. 
HORN, L. Metalinguistic Negation and Pragmatic Ambiguity. Language, v. 61, n. 1, p. 121-174, 1985.

HORN, L. A Natural History of Negation. Stanford, CA: CSLI, 1989.

HORN, L. Economy and Redundancy in a Dualistic Model of Natural Language. In: SHORE, S.; VIKUNA, M. (Ed.). Sky 1993: Yearkbook of the Linguistic Association of Finland, 1993, p. 31-74.

HORN, L. The Border Wars: a Neo-Gricean Perspective. In: von HEUSINGER, K.; TURNER, K. (Ed.). Where Semantics Meets Pragmatics, Oxford: Elsevier, 2006. p. 21-48.

HORN, L. Neo-Gricean Pragmatics: a Manichaean Manifesto. In: BURTON-ROBERTS, N. (Ed.). Pragmatics. Basingstoke: Palgrave Macmillan, 2007. p. 158-183.

HUANG, Y. Neo-Gricean Pragmatics and the Lexicon. Internacional Review of Pragmatics, v. 1, p. 118-153, 2009.

JESPERSEN, O. Negation in English and Other Languages. Kobenhavn: Biando Lunos Bogtrykkeri, 1917.

KIPARSKY, P.; CONDORAVDI, C. Tracking Jespersen's Cycle. In: JANSE, M.; JOSEPH, B. D.; RALLI, A. (Ed.). Proceedings of the $2^{\text {nd }}$ MGDLT. Mytilene: Doukas, 2006.

KRÖLL, H. Sobre nada e algumas expressões equivalentes em português. Revista Brasileira de Filologia, t. XII, 1952.

KURYLOWICZ, J. L'Évolution des categories grammaticales. In: Problèmes du langage. Paris: Gallimard, 1966. p. 55-71.

LACAN, J. Fonction et champ de la parole e du langage en psychanalyse. Écrits I, Paris: Seuil, 1966a.

LACAN, J. Du traitement possible de la psychose. Écrits II, Paris: Seuil, 1966b. LANGACKER, R. W. Subjectification. Cognitive Linguistics, n. 1, p. 5-38, 1990.

LANGACKER, R. W. Subjectification, Grammaticization and Conceptual Arquetypes. In: ATHANASIADOU, A.; CANAKIS, C.; CORNILLIE, B. (Ed.). Subjectification. Various Paths to Subjectivity. Berlin: Mouton de Gruyter, 2006.

LEVINSON, S. Presumptive Meaning: The Theory of Generalized Conversational Implicature. Cambridge, MA: MIT Press, 1991a. 
LEVINSON, S. Pragmatic Reduction of the Binding Conditions Revisited. Journal of Linguistics, v. 27, p. 107-161, 1991 b.

LEVINSON, S. Pragmática. São Paulo: Martins Fontes, 2007.

LIBERA, A. de. La querelle des universaux. De Platon à fin du Moyen Age. Paris: Seuil, 1996.

LIGHTFOOT, D. Principles of Diachronic Syntax. Cambridge: Cambridge University Press, 1979.

MAQUIAVEL, N. O Príncipe. São Paulo: Abril Cultural, 1983 (=1515). (Coleção Os Pensadores)

MARTIN, R. Le fantome du nom abstrait. In: FLAUX, N.; GLATIGNY, M.; SAMAIN, D. (Éd.). Les noms abstraits. Histoire et theories. Paris: Presses Universitaires du Septentrion, 1996. p. 41-50.

MATTOSO CÂMARA, J. Sôbre o futuro romance. Revista Brasileira de Filologia, n. 3, p. 221-225, 1956.

MATTOSO CÂMARA, J. Dicionário de linguística e gramática. Petrópolis: Vozes, 1985.

MAURER JR., T. Dois problemas da língua portuguesa. O infinito pessoal e o pronome SE. São Paulo, 1951.

MEAD, G. H. L'Esprit, le Soi et la Société. Paris: PUF, 2006 (=1934).

MEILLET, A. L'évolution des formes grammaticales. In: MEILLET, A. Linguistique Historique et Linguistique Générale. Paris: Champion, 1982 (=1912). p. 130-148.

MEILLET, A. Esquisse d'une histoire de la langue latine. Paris: Hachette, 1928.

MEYER-LÜBKE, W. Introduccion al estudio de la lingüistica romance. Madrid: Tip. de la Revista de Archivos, Bibliotecas y Museos, 1914 (=1909).

MILROY, L. Language and Social Networks. Oxford: Blackwell, 1980. NARO, A. The Genesis of the Reflexive Impersonal in Brazilian Portuguese: a Study in Syntactic Change as a Surface Phenomenon. Language, v. 52, n. 4, p. 779-810, 1976.

NUNES, J. O famigerado SE: uma análise sincrônica e diacrônica das construções com se apassivador e indeterminador. 1990. Dissertação (Mestrado) - Unicamp, Campinas, 1990. 
PRICE, E. The ZPG Letter: Subjects, Definiteness, and Informationstatus. In: THOMPSON, S.; MANN, W. (Ed.). Discourse, Description: Diverse Analyses of a Fundraising Text. Amsterdam: Benjamins, 1992. p. 295-325.

RAJAGOPALAN, K. Negation and Denial. A Study in the Theory of Speech Acts. 1982. Tese (Doutorado) - PUC-SP, São Paulo, 1982.

RONCARATI, C. A negação no português falado. In: MACEDO, A. T. et al. (Org.). Variação e discurso. Rio de Janeiro: Tempo Brasileiro, 1999. p. 65-102.

ROSCH, E. Principes of Categorization. In: ROSCH, E.; LLOYD, B. (Ed.). Cognition and Categorization. New Jersey: Lawrence Erlbaum Associates Publishers, 1978.

SAPIR, E. Language: An Introduction to the Study of Speech. New York: Harcourt, Brace, 1921.

SCHWEGLER, A. Predicate Negation in Contemporary Brazilian Portuguese: a linguistic change in progress. Orbis, v. 34, p. 187-214, 1991.

SCHWENTER, S. The Pragmatics of Negation in Brazilian Portuguese. Lingua, v. 115, p. 1427-1456, 2005.

SOUSA, L. Sintaxe e interpretação de negativas sentenciais no português brasileiro. 2012. Tese (Doutorado) - Unicamp, Campinas, 2012.

SOUSA, L.; Formas Reduzidas do item 'Não' no Português Brasileiro. In: VITRAL, L; COELHO, S. (Org.). Estudos de processos de gramaticalização em português. Metodologias e aplicações. Campinas: Mercado de Letras, 2010.

SOWA, J. Categorization in Cognitive Computer Science. In: COHEN, H.; LEFEBVRE, C. (Ed.). Handbook of Categorization in Cognitive Science. Amsterdam: Elsevier, 2005.

TRAUGOTT, E.; DASHER, R. B. Regularity in Semantic Change. Cambridge: Cambridge University Press, 2005.

VIANNA, H. L. G. A estrutura modal+infinitivo em português: gramaticalização e modalização. 2000. Dissertação (Mestrado) Faculdade de Letras da UFMG, Belo Horizonte, 2000.

VITRAL, L. A negação: teoria da checagem e mudança lingüística. D.E.L.T.A., v. 15, n. 1, p. 57-84, 1999. 
VITRAL, L. A evolução do se reflexivo em português na perspectiva da gramaticalização. In: LOBO, T. et al. (Org.). Para a história do português brasileiro. v. 6. Salvador: EDUFBA, 2006. p. 107-133.

VITRAL, L.; J. RAMOS. Gramaticalização: uma abordagem formal. Rio de Janeiro: Tempo Brasileiro/FALE-UFMG, 2006.

VITRAL, L. A inovação linguística: subjetificação e luta por reconhecimento. Revista de Estudos da Linguagem, Belo Horizonte, v. 20 n. 1, p. 65-98, 2012.

VOSSLER, K. Neue Denkformen im Vulgärlatein. In: Hauptfragen der Romanistik. Festschrift für Philipp August Becker. Heidelberg: Winter, 1922. p. 170-191.

WILMET, M. À la recherche du Nom Abstrait. In: FLAUX, N.; GLATIGNY, M.; SAMAIN, D. (Éd.). Les Noms Abstraits. Histoire et theories. Paris: Presses Universitaires du Septentrion, 1996. p. 67-76.

WINNICOTT, D. W. O brincar e a realidade. Rio de Janeiro: Imago, 1975. 
